\title{
ON THE ULTIMATE COMPRESSIVE STRENGTH OF TRANSVERSELY CRACKED PLATES
}

\author{
Abbas Bayatfar \\ ArGEnCo Department-ANAST \\ University of Liege \\ Liège, Chemin des Chevreuils 1 (B52/3), Belgium
}

\author{
Timothee Pire \\ ArGEnCo Department-ANAST \\ University of Liege \\ Liège, Chemin des Chevreuils 1 (B52/3), Belgium
}

\author{
Philippe Rigo \\ ArGEnCo Department-ANAST \\ University of Liege \\ Liège, Chemin des Chevreuils 1 (B52/3), Belgium
}

\begin{abstract}
This paper aims to numerically analyse the ultimate strength of transversely cracked steel plates under longitudinal compressive loading, considering the effect of initial distortion as well. The main objective of this study is to investigate the ultimate compressive strength characteristics of an unstiffened steel plate due to transverse cracking damages located in the middle (i.e. centre cracks and edge cracks). To achieve that, a series of non-linear finite element (FE) analyses are carried out using ANSYS commercial finite element code. The obtained FE results are discussed to indicate the amount of crack influence, in terms of its length and location, on the ultimate compressive strength of a steel plate element with different thicknesses.
\end{abstract}

\section{KEYWORDS}

Ultimate strength; longitudinal compression; cracked steel plates; FEM.

\section{INTRODUCTION}

A significant feature of ship design is the ability to describe the structural behaviour of a ship hull girder and to accurately predict its maximum load-carrying capacity. On the other hand, plates are one of the dominant structural components in all ship and offshore applications. Hence the ultimate strength evaluation of this component is of crucial importance for the safety assessment and economical design of a ship structure. In this regard, it is required to consider all the parameters and factors involved over fabrication process and service life. Among them, the influence of initial distortion and crack defects may be mentioned which must be taken them into account.

A large number of studies have been performed to investigate the influence of initial imperfections on strength characteristics of steel-plated components (e.g. Paik et al., 2004 and 2009). Also, numerous investigations have been carried out concerning the cracking damage, but most of them dealt with it from fatigue limit state point of view (e.g. Fang et al. 2010 and Xiao-dong 2010). Nevertheless, the available literature on structural behaviour of crack-plated components under monotonic loading are quite limited (e.g. Brighenti et al. 2005, Alinia et al. 2007 and Khedmati et al. 2009). The ultimate strength of cracked steel plates under monotonic loading has received some attention in recent years by a few investigators among them should be mentioned Paik et al. (2005, 2008 and 2009). However, in line with the importance of this topic and the limited availability references on it, seems that further studies are required to a systematically investigation. In this regard, this paper presents numerical study carried out on the ultimate compressive strength of transversally cracked steel plates, considering the effects of initial distortion as well. The main objective of this study is to investigate the ultimate compressive strength characteristics of an unstiffened steel plate due to transverse cracking damages located in the middle (i.e. centre cracks and edge cracks). To achieve that, a series of nonlinear finite element (FE) analyses are carried out using ANSYS commercial finite element code. The obtained FE results are discussed to indicate the amount of crack influence, in terms of its length and location, on the ultimate compressive strength of a steel plate element with different thicknesses.

\section{MODELS FOR ANALSIS}

\section{Extent and Geometry}

The plate element was taken from Ship Structure Committee report (1997; SSC-399) which is shown in Fig. 1 along with their related $X Y Z$ co-ordinate system. This plate model is $2000 \mathrm{~mm}$ and $500 \mathrm{~mm}$ in length (a) and breadth (b), respectively. In the present study, different values of thickness were taken into considerations which are 8.5, 10, 13 and 16 $\mathrm{mm}$. 


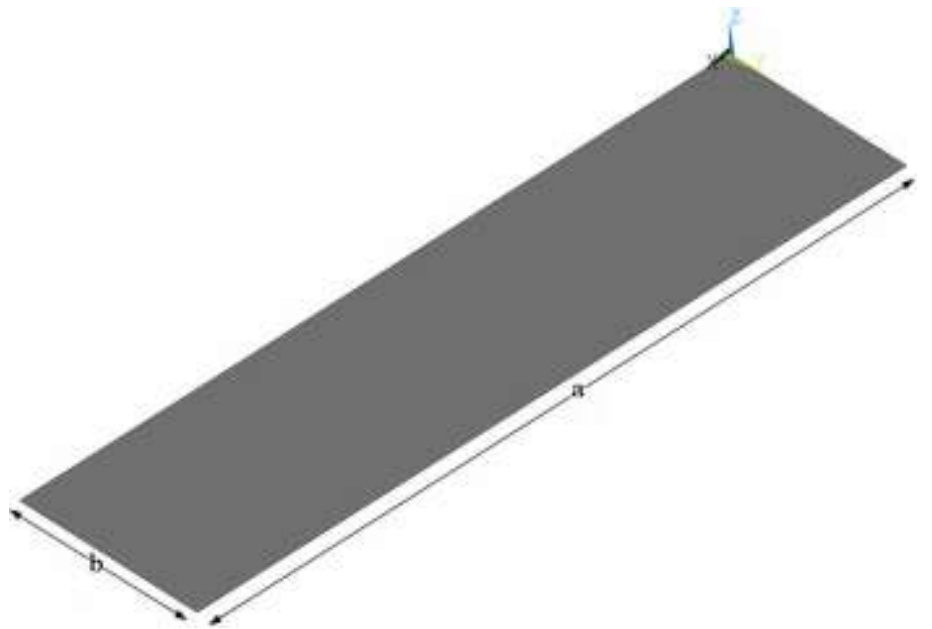

Fig. 1. Plate model

In order to consider the locations of transverse crack defects, the two models shown in Fig. 2 were taken. These models were also divided into different cases (in terms of crack lengths) for the analysis purposes. The crack lengths are assumed to be a certain proportion of the plate breadth with size ranging from $2 c / b=0.1$ to 0.5 , where $2 c$ is the crack length and $b$ is the plate breadth. The analysed cases are described with some details below:

- The plate case in which the crack transversally (Y-axis direction) located in the middle of plate (Fig. 2-a), called as 'UTC' (e.g. UTC10\% meaning that the crack length is $10 \%$ of the plate breadth).

- The plate case in which two cracks transversally located in longitudinal edges (Fig. 2-b) and their lengths (c) altered from 0.1 to 0.5 of half the plate breadth. This case called as 'UT2E' (e.g. UT2E10\% meaning that the crack length $(c)$ is $10 \%$ of half the plate breadth).

It should be noted that here is only taken the through-thickness cracking for pessimistic considerations in which the size of gap (between crack faces) is $3 \mathrm{~mm}$.

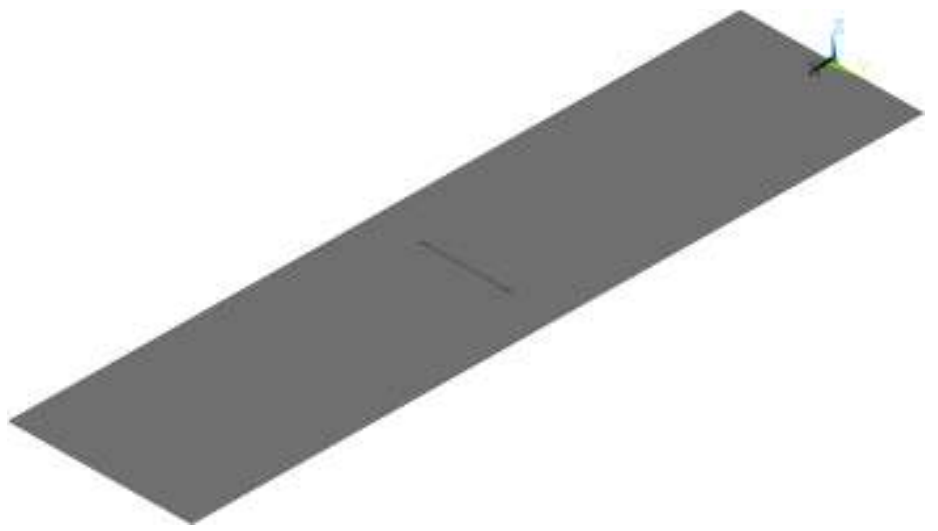

a) UTC

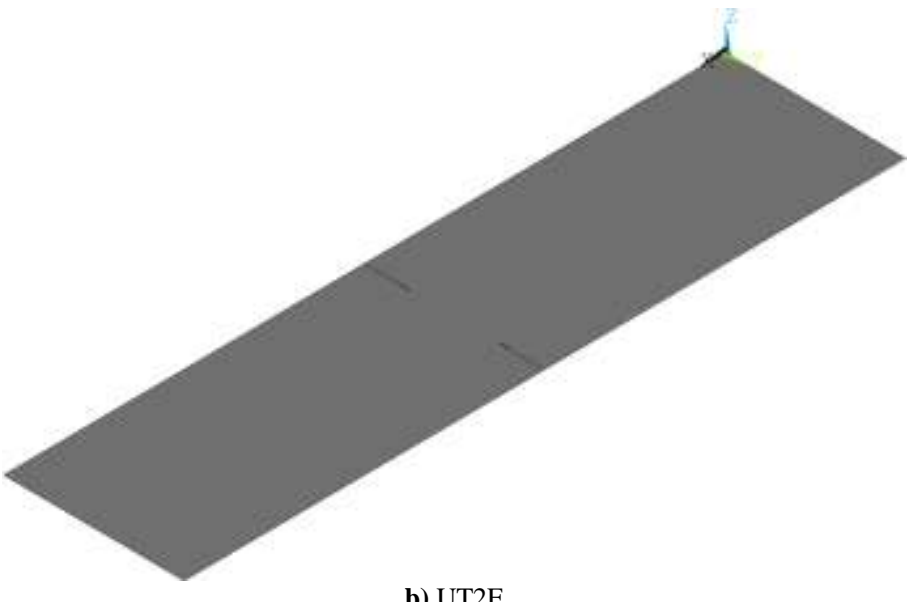

b) UT2E

Fig. 2. Plate model with various locations of transverse crack defect

In addition, there is another analysed case without any cracks as reference model which is taken in order to establish a comparison basis for damaged cases. In other words, in order to examine the effect of cracking damage on ultimate compressive strength characteristics of plate element. This model is called as 'REF' henceforth.

\section{Mechanical Properties of Material}

The material used in this work is of a high strength steel alloy which was taken from Ship Structure Committee report (1997; SSC-399). The mechanical properties of material are given in Table 1 in which $E, v$ and $\sigma_{Y}$ are modulus of elasticity, Poisson's ratio and yield stress, respectively.

Table 1

Summary of material properties

\begin{tabular}{lcr}
\hline$E$ & $v$ & $\sigma_{Y}$ \\
\hline $\mathrm{MPa}$ & - & $\mathrm{MPa}$ \\
200472 & 0.3 & 425 \\
\hline
\end{tabular}

In this regard, an elastic-hardening plastic material model was assumed to apply in FE modelling. Fig. 3 shows the average stress-average strain curve of material. 


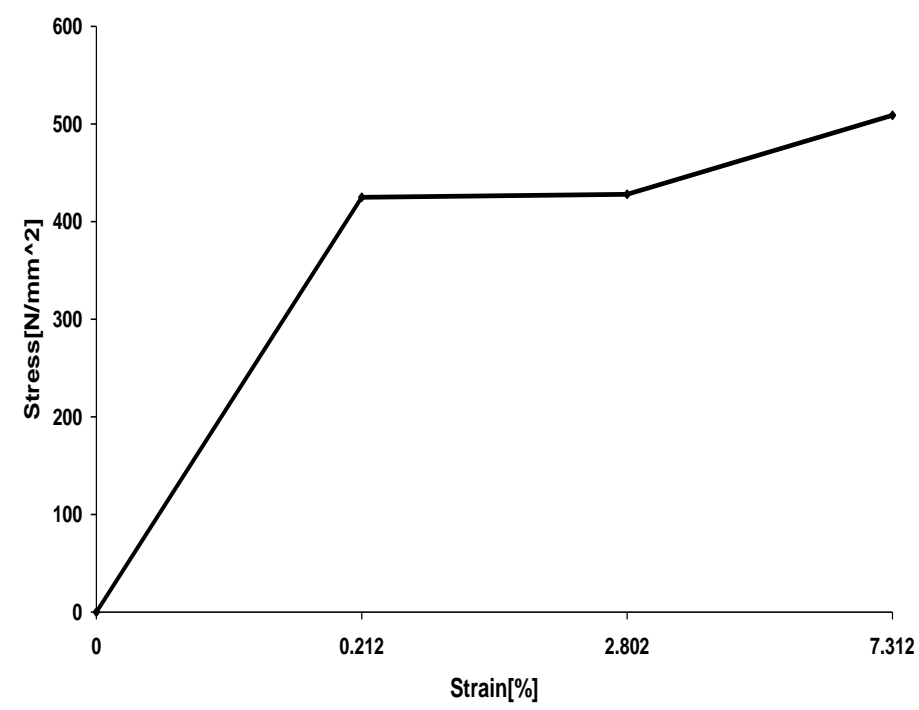

Fig. 3. Average stress-average strain curve of material

\section{Selection of Element Type (FE)}

In this regard, the ANSYS commercial finite element code (version 12.1; 2009) is used. Among the elements included in the ANSYS library, the SHELL181 element (Fig. 4) is selected in order to discretise the cracked steel plate models.

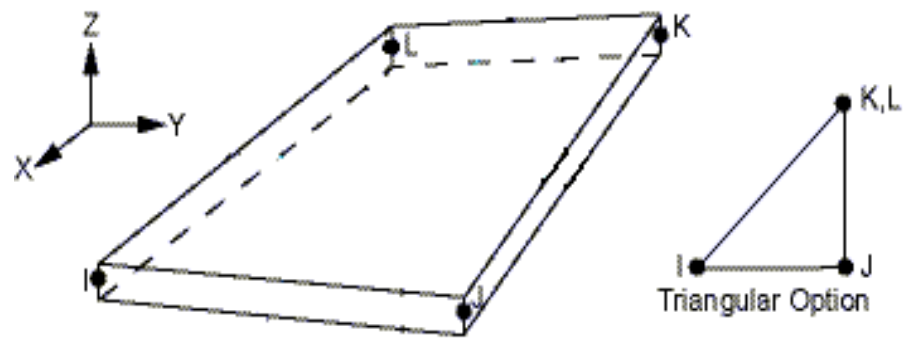

Fig. 4. SHELL181 element

SHELL181 is suitable for analysing thin to moderatelythick shell structures which falls into the domain of plate thicknesses used for ship building. It is a 4-node element with six degrees of freedom at each node: translations in the $\mathrm{X}, \mathrm{Y}$, and $\mathrm{Z}$ directions, and rotations about the $\mathrm{X}, \mathrm{Y}$, and $\mathrm{Z}$-axes. This element is well-suited for linear, large rotation, and/or large strain non-linear applications (ANSYS 2009). Fig. 5 shows a typical coarse mesh generation used in non-linear finite element analysis.

\section{Initial Distortion}

In the present study, the initial distortion shape of plating was considered as buckling mode using the equation $\omega_{0}=\omega_{0 p l} \sin (m \pi x / a) \sin (\pi y / b)$ in which $\omega_{0 p l}$ is equal to

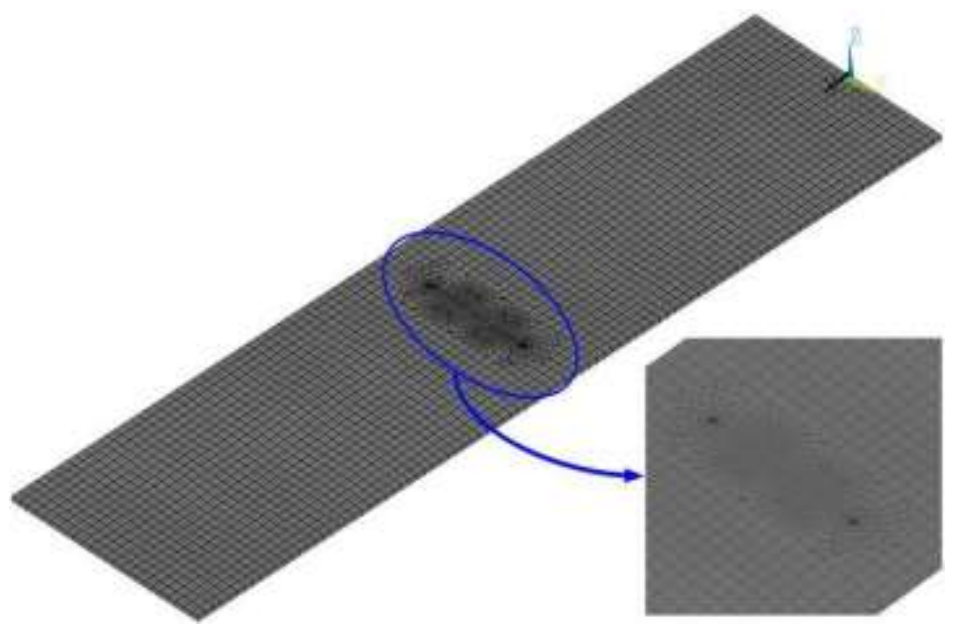

Fig. 5. A typical coarse mesh generation for UTC50\% model

$0.1 \beta^{2} t \quad$ (Paik et al. 2004). By substituting the plate slenderness ( $\beta=(b / t) \sqrt{\sigma_{Y} / E}$ ), the final equation of plating initial distortion is obtained as $\omega_{0}=5.3 \sin (\pi x / 500) \sin (\pi y / 500)$ to apply in finite element modelling. Fig. 6 shows a typical plating initial distortion (with magnification of $\mathrm{x} 10$ ) for model 'UTC'.

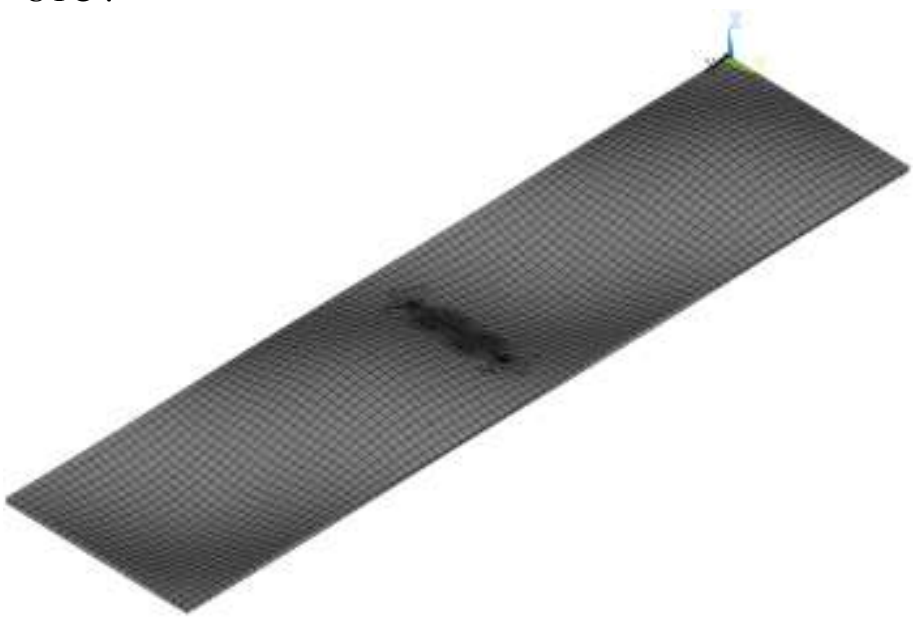

a) Isometric view

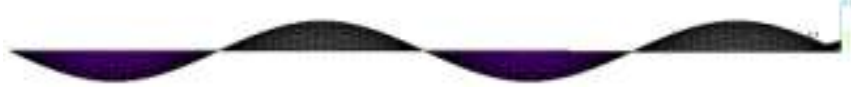

b) Side view

Fig. 6. Typical initial distortion for UTC model $(\times 10)$ 


\section{Boundary Conditions}

The cases study were assumed to be simply supported along all edges. More information regarding the state of boundary conditions is given in the illustrative case shown in Fig. 7.

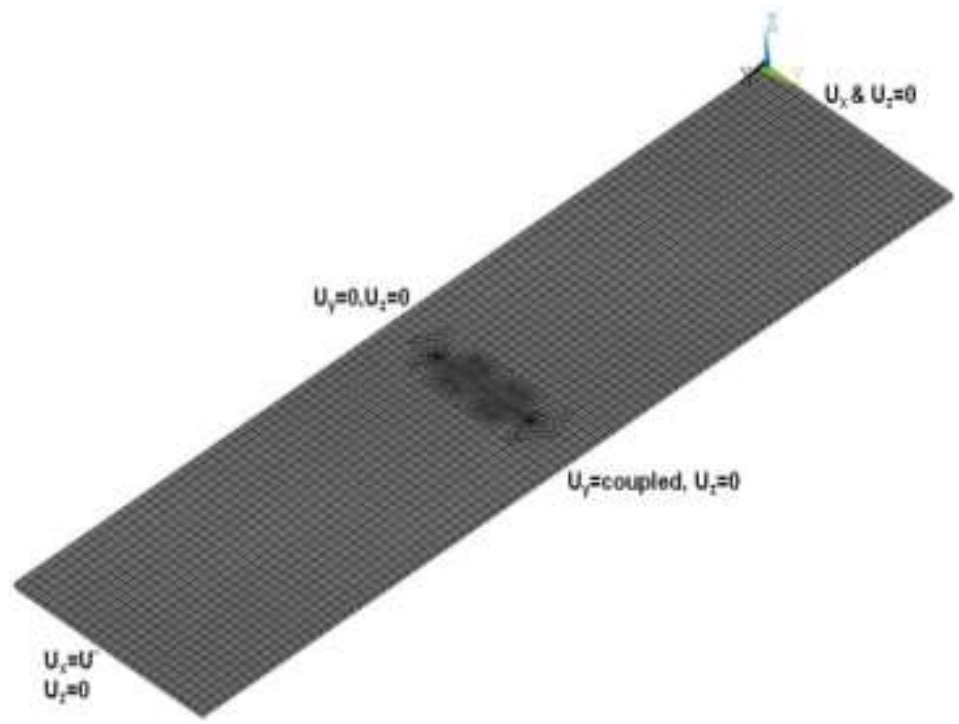

Fig. 7. Typical boundary conditions for UTC50\% model

\section{FINITE ELEMENT ANALYSIS}

The ANSYS commercial FE code (employing NewtonRaphson method) was used to perform non-linear analyses of cases study under longitudinal axial compressive loading. The monotonic loading was simulated through an imposed displacement as shown in Fig. 7. All nodes, along forward transverse edge are grouped together to have equal displacement along longitudinal direction ( $X$-axis $)$.

\section{Convergence Study}

In order to determine the best size of elements based on a compromise between computational cost and accuracy, two types of mesh generations were considered which are called 'Coarse Mesh' and 'Fine Mesh'. First, a coarse mesh generation with the total number of 2872 elements in which the size of elements were taken around $21 \mathrm{~mm}$ away from the existing crack, and more finer around the crack (see Fig. 8-a). Then, a fine mesh generation with the total number of 10334 elements in which the size of elements were approximately halved to $10 \mathrm{~mm}$ away from the existing crack, and the size and distribution of elements were kept almost similar around the crack (see Fig. 8-b). In both cases, it has been attempted to have elements with an aspect ratio nearly unity as much as possible.

As it can be seen in Table 2, there is no significant difference between the obtained values of ultimate strengths. As a result of such a convergence study, the case of 'Coarse Mesh' was chosen and the rest of mesh generations for the other analysed cases are on this basis.
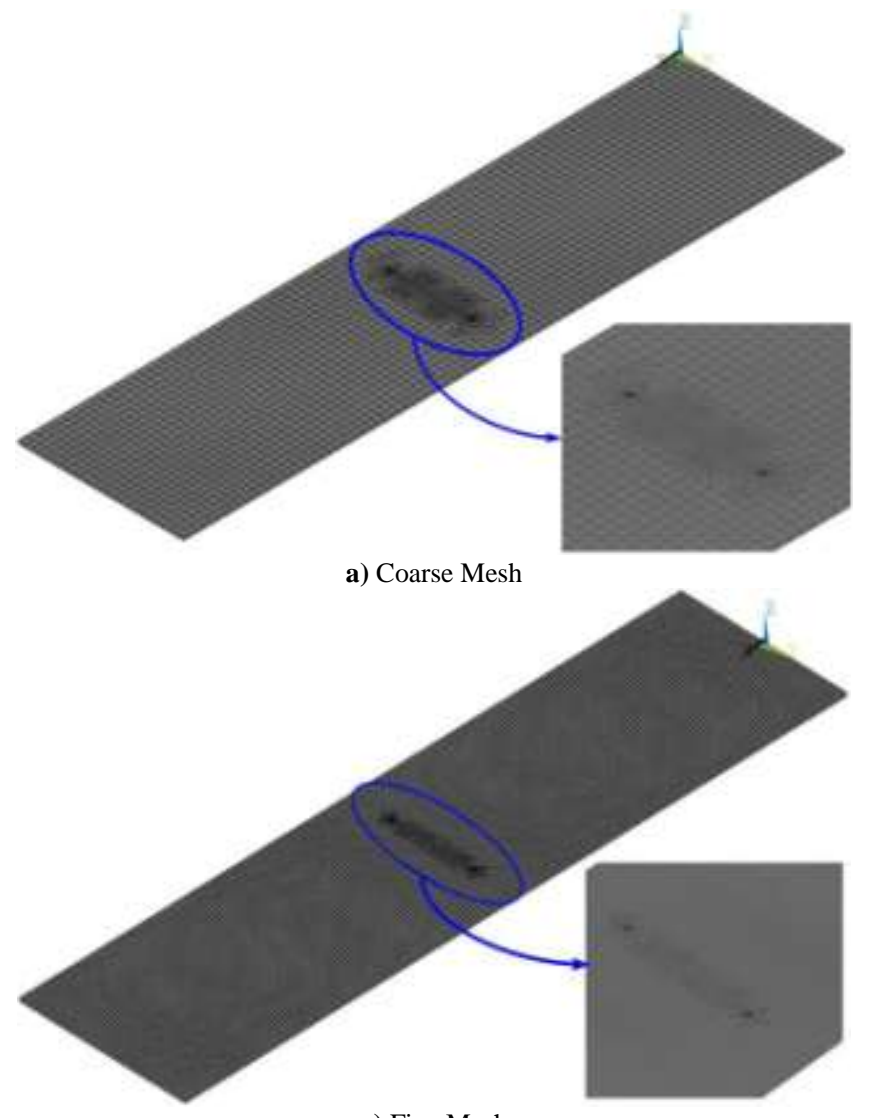

a) Fine Mesh

Fig. 8. Mesh generations for UTC50\% model

Table 2

Values of ultimate strengths in both Coarse and Fine Mesh cases

\begin{tabular}{ccc}
\hline Case & Ultimate strength(MPa) & Difference $^{I}(\%)$ \\
\hline Coarse Mesh & 245.2 & - \\
Fine Mesh & 252.7 & +3 \\
\hline
\end{tabular}

\section{Model Verification}

Prior to starting nonlinear finite element analyses, sensitivity of the ultimate strength values for two typical models with the both Newton-Raphson and Arc-length methods are studied. The results of this sensitivity analysis are reported in Table 3. This was mainly done because no relevant and useful databases of experimental results and/or existing theoretical and numerical computations had been reported previously, according to the researchers' knowledge and literature survey. In Newton-Raphson method, longitudinal axial compressive

\footnotetext{
${ }^{1}$ Compared with Coarse Mesh case
} 
loading has been simulated through either displacement control or force control that are respectively called as 'NR-D' and 'NRF' in Table 3; whilst the imposed displacement control was adopted in the Arc-length method, that is called as 'AL-D' in Table 3. As it can be seen from this table, there is no significant difference in accuracy between the obtained values of the ultimate strengths through selection of these two foregoing methods.

Table 3

Obtained values of ultimate strengths through different methods

\begin{tabular}{cccc}
\cline { 2 - 4 } & \multicolumn{3}{c}{ UTC50\% } \\
\cline { 2 - 4 } & NR-D & NR-F & AL-D \\
\hline Ultimate strength $(\mathrm{MPa})^{2}$ & 245.2 & 248.9 & 248.2 \\
Difference $^{2}(\%)$ & - & +1.5 & +1.2 \\
\hline
\end{tabular}

\section{Results and Discussion}

The cases study given in Fig. 2 have been analysed through 'NR-D' procedure since it's more suitable. After performing the non-linear finite element analysis for all of the cases study, the following results and observations have been obtained.

$>$ Non-dimensional average stress-average strain curves (shown in Figs. 9-12) indicate that, for the plate thicknesses 8.5 and $10 \mathrm{~mm}$, the reduction of the ultimate strength (compared with reference model) can be considerable for UTC50\% model (i.e. when the crack length is equal to the half of plate width ' $250 \mathrm{~mm}$ '). In the cases with plate thicknesses 13 and $16 \mathrm{~mm}$, the critical crack length (which may considerably reduce the value of ultimate strength) can be equal or more than $150 \mathrm{~mm}$.

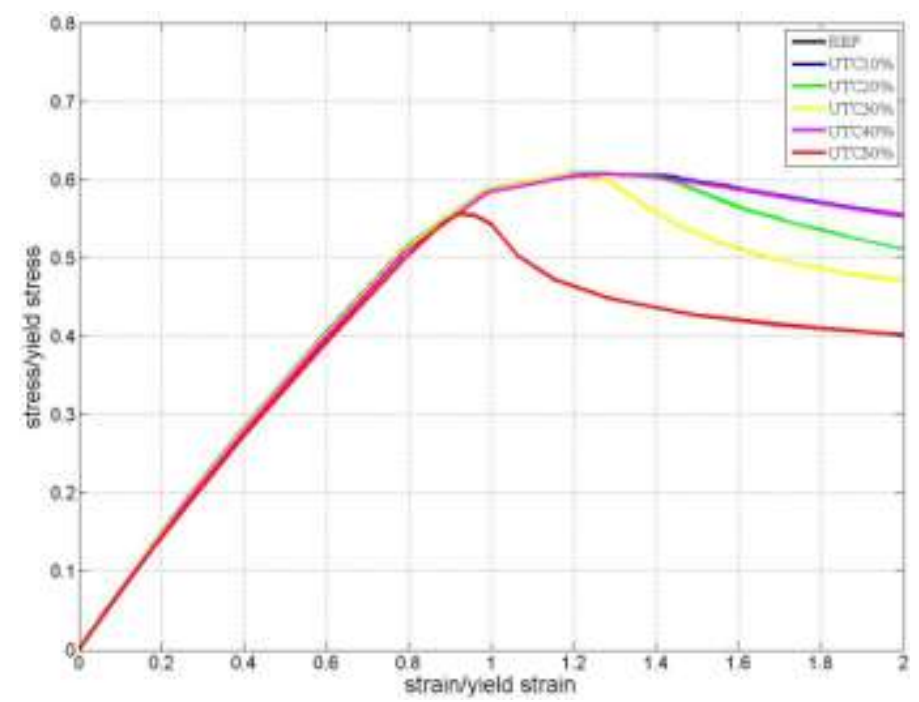

Fig. 9. Non-dimensional average stress-average strain curves for UTC Models $(\mathrm{t}=8.5 \mathrm{~mm})$

\footnotetext{
${ }^{2}$ Compared with NR-D method
}

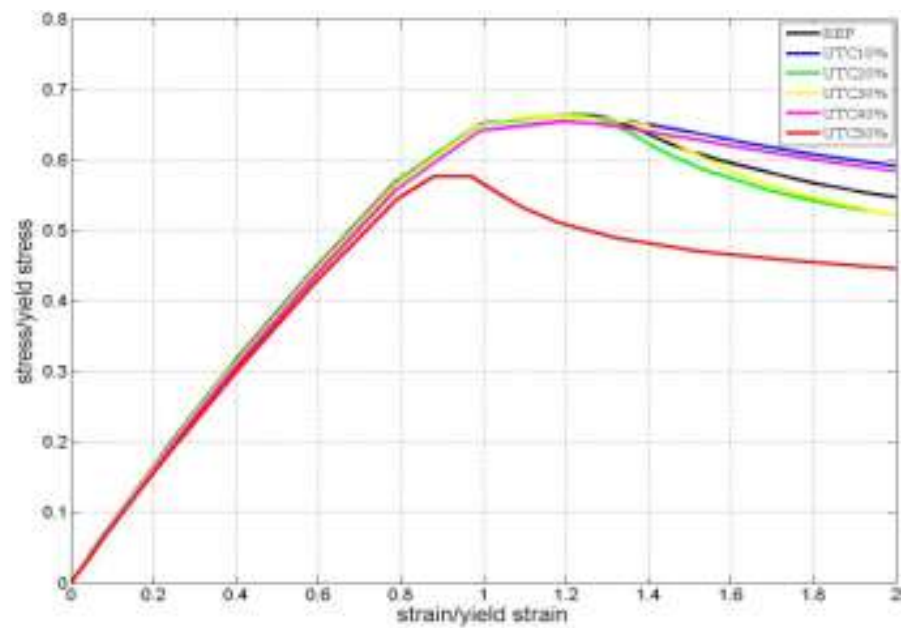

Fig. 10. Non-dimensional average stress-average strain curves for UTC Models $(\mathrm{t}=10 \mathrm{~mm})$

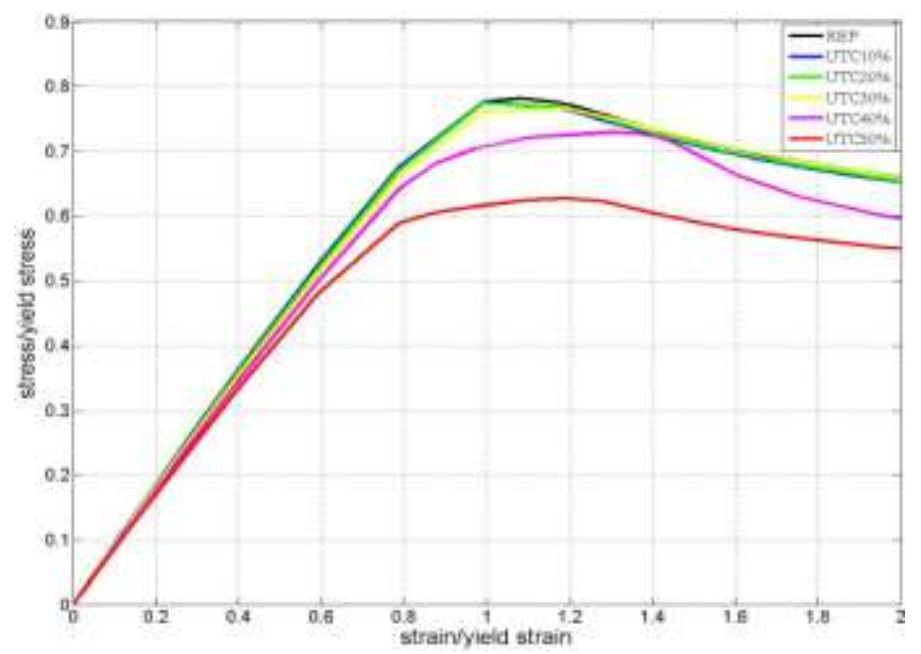

Fig. 11. Non-dimensional average stress-average strain curves for UTC Models ( $\mathrm{t}=13 \mathrm{~mm}$ )

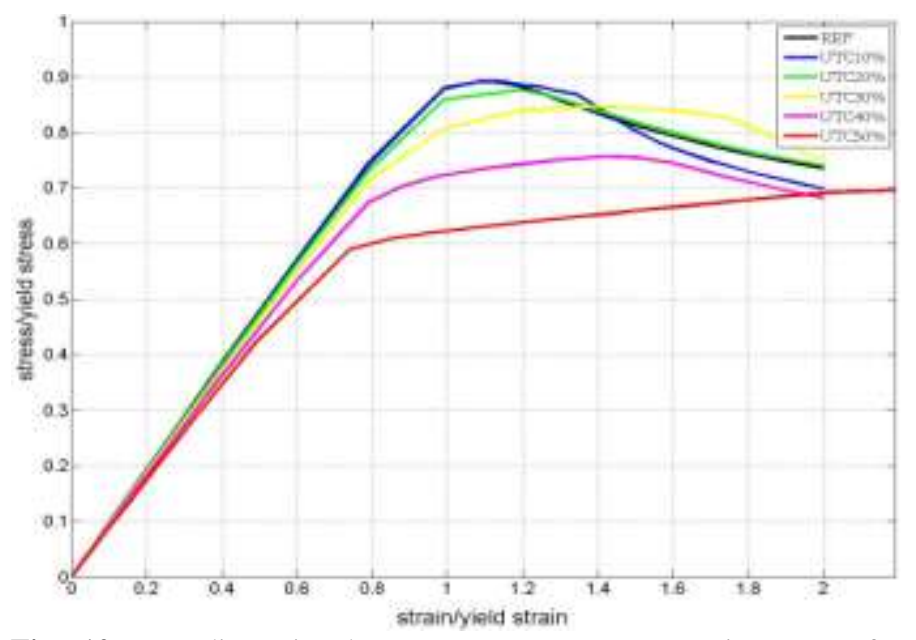

Fig. 12. Non-dimensional average stress-average strain curves for UTC Models ( $\mathrm{t}=16 \mathrm{~mm})$ 
$>$ Non-dimensional average stress-average strain curves (shown in Figs. 13-16) indicate that for UT2E models with different thickness, the critical crack length is more than 50 $\mathrm{mm}$. In other words, the ultimate strength reduction can be considerable for all UT2E models except UT2E10\%.

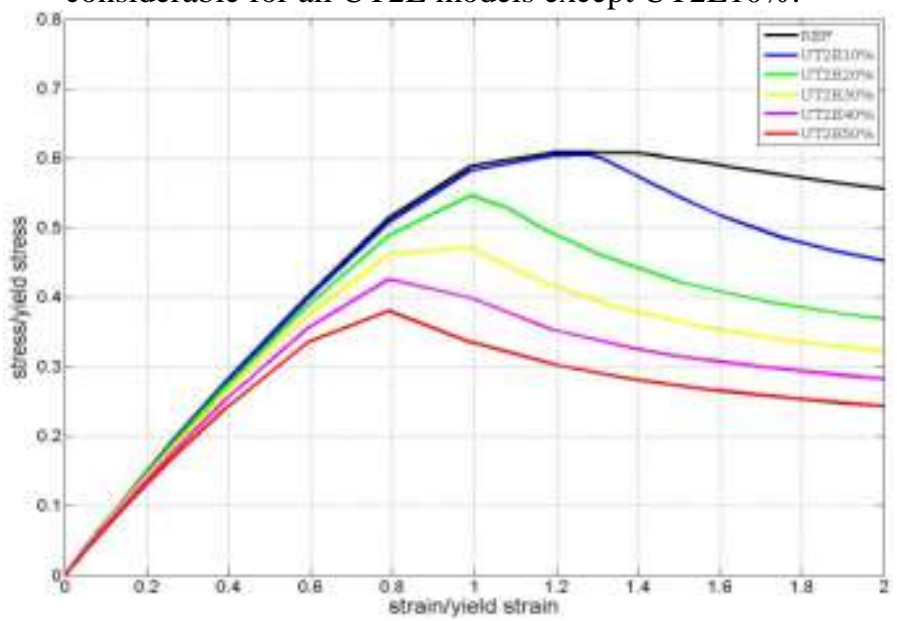

Fig. 13. Non-dimensional average stress-average strain curves for UT2E Models ( $\mathrm{t}=8.5 \mathrm{~mm})$

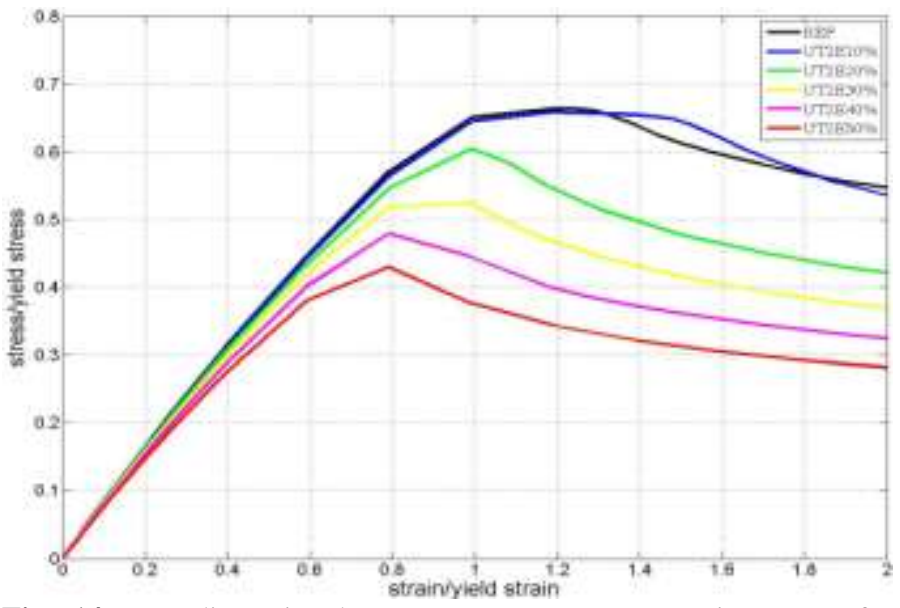

Fig. 14. Non-dimensional average stress-average strain curves for UT2E Models ( $\mathrm{t}=10 \mathrm{~mm})$

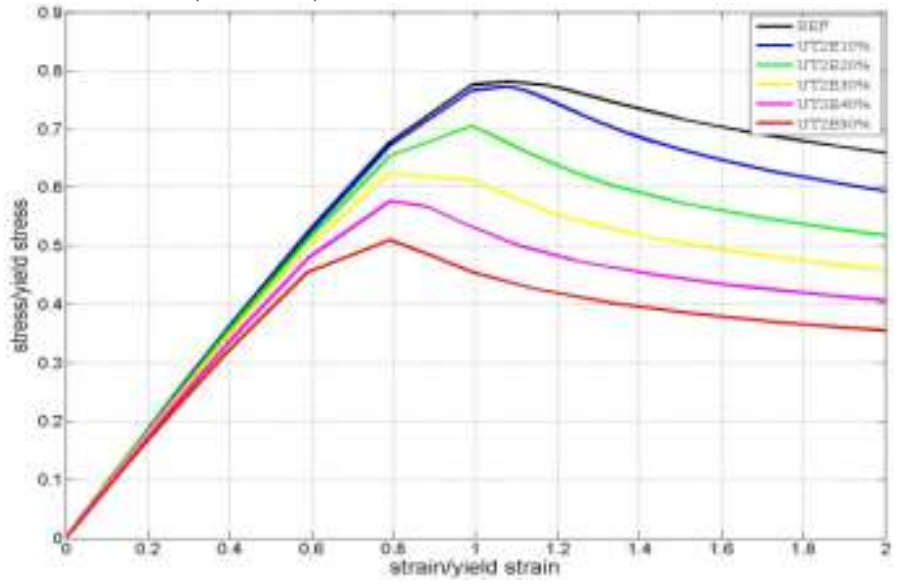

Fig. 15. Non-dimensional average stress-average strain curves for UT2E Models ( $\mathrm{t}=13 \mathrm{~mm})$

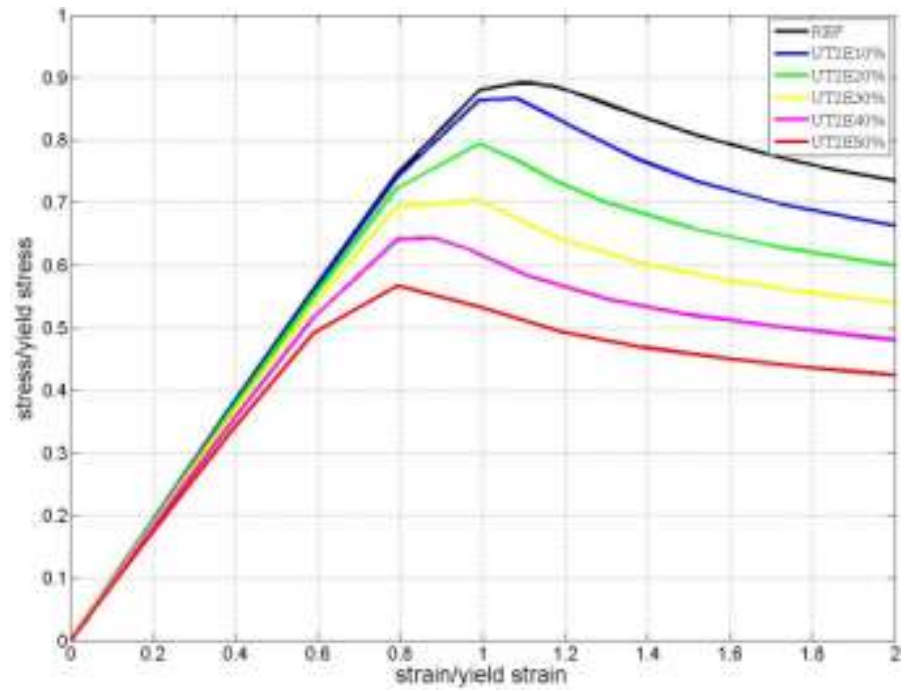

Fig. 16. Non-dimensional average stress-average strain curves for UT2E Models ( $\mathrm{t}=16 \mathrm{~mm})$

> Tables 5-9 show the values of ultimate strengths for the different UTC models with different thicknesses, in comparison with the value obtained for the thickness 8.5 $\mathrm{mm}$. As it can be seen, the increase rate of ultimate strengths are quite similar for models 'UTC10\%', 'UTC20\%' and 'UTC30\%' when the plate thickness is increased. This is while the increase rate of ultimate strengths are reduced for model 'UTC40\%' and more for model 'UTC50\%' when the plate thickness is increased.

\section{Table 5}

Ultimate strength values for UTC10\% Model with different thicknesses

\begin{tabular}{ccccc}
\hline Plate thickness $(\mathrm{mm})$ & $\mathbf{8 . 5}$ & $\mathbf{1 0}$ & $\mathbf{1 3}$ & $\mathbf{1 6}$ \\
\hline Ultimate strength $(\mathrm{MPa})$ & 258.5 & 282.2 & 329.7 & 378.9 \\
Difference $(\%)$ & - & 8.4 & 21.6 & 31.8 \\
\hline
\end{tabular}

Table 6

Ultimate strength values for UTC20\% Model with different thicknesses

\begin{tabular}{ccccc}
\hline Plate thickness $(\mathrm{mm})$ & $\mathbf{8 . 5}$ & $\mathbf{1 0}$ & $\mathbf{1 3}$ & $\mathbf{1 6}$ \\
\hline Ultimate strength $(\mathrm{MPa})$ & 258.4 & 282.2 & 329.1 & 372.7 \\
Difference $(\%)$ & - & 8.4 & 21.5 & 30.7 \\
\hline
\end{tabular}

Table 7

Ultimate strength values for UTC30\% Model with different thicknesses

\begin{tabular}{ccccc}
\hline Plate thickness $(\mathrm{mm})$ & $\mathbf{8 . 5}$ & $\mathbf{1 0}$ & $\mathbf{1 3}$ & $\mathbf{1 6}$ \\
\hline Ultimate strength (MPa) & 258.2 & 281.8 & 325.4 & 360 \\
Difference (\%) & - & 8.4 & 20.7 & 28.3 \\
\hline
\end{tabular}


Table 8

Ultimate strength values for UTC40\% Model with different thicknesses

\begin{tabular}{ccccc}
\hline Plate thickness $(\mathrm{mm})$ & $\mathbf{8 . 5}$ & $\mathbf{1 0}$ & $\mathbf{1 3}$ & $\mathbf{1 6}$ \\
\hline Ultimate strength $(\mathrm{MPa})$ & 258.3 & 278.2 & 309.9 & 321.5 \\
Difference $(\%)$ & - & 7.2 & 16.7 & 19.7 \\
\hline
\end{tabular}

Table 9

Ultimate strength values for UTC50\% Model with different thicknesses

\begin{tabular}{ccccc}
\hline Plate thickness (mm) & $\mathbf{8 . 5}$ & $\mathbf{1 0}$ & $\mathbf{1 3}$ & $\mathbf{1 6}$ \\
\hline Ultimate strength (MPa) & 236.6 & 245.2 & 266.6 & 295.5 \\
Difference $(\%)$ & - & 3.5 & 11.3 & 19.9 \\
\hline
\end{tabular}

$>$ Tables 10-14 show the values of ultimate strengths for the different UT2E models with different thicknesses, in comparison with the value obtained for the thickness 8.5 $\mathrm{mm}$. As it can be seen, the increase rate of ultimate strengths are quite similar for all models when the plate thickness is increased.

\section{Table 10}

Ultimate strength values for UT2E10\% Model with different thicknesses

\begin{tabular}{ccccc}
\hline Plate thickness $(\mathrm{mm})$ & $\mathbf{8 . 5}$ & $\mathbf{1 0}$ & $\mathbf{1 3}$ & $\mathbf{1 6}$ \\
\hline Ultimate strength $(\mathrm{MPa})$ & 257 & 280.1 & 328.4 & 368.5 \\
Difference $(\%)$ & - & 8.2 & 21.7 & 30.3 \\
\hline
\end{tabular}

\section{Table 11}

Ultimate strength values for UT2E20\% Model with different thicknesses

\begin{tabular}{ccccc}
\hline Plate thickness $(\mathrm{mm})$ & $\mathbf{8 . 5}$ & $\mathbf{1 0}$ & $\mathbf{1 3}$ & $\mathbf{1 6}$ \\
\hline Ultimate strength $(\mathrm{MPa})$ & 232.2 & 256.8 & 300 & 337.7 \\
Difference $(\%)$ & - & 9.6 & 22.6 & 31.2 \\
\hline
\end{tabular}

\section{Table 12}

Ultimate strength values for UT2E30\% Model with different thicknesses

\begin{tabular}{ccccc}
\hline Plate thickness $(\mathrm{mm})$ & $\mathbf{8 . 5}$ & $\mathbf{1 0}$ & $\mathbf{1 3}$ & $\mathbf{1 6}$ \\
\hline Ultimate strength $(\mathrm{MPa})$ & 200.5 & 223 & 265.5 & 298.9 \\
Difference $(\%)$ & - & 10.1 & 24.5 & 32.9 \\
\hline
\end{tabular}

\section{Table 13}

Ultimate strength values for UT2E40\% Model with different thicknesses

\begin{tabular}{ccccc}
\hline Plate thickness $(\mathrm{mm})$ & $\mathbf{8 . 5}$ & $\mathbf{1 0}$ & $\mathbf{1 3}$ & $\mathbf{1 6}$ \\
\hline Ultimate strength $(\mathrm{MPa})$ & 181 & 203.9 & 245.2 & 273.7 \\
Difference $(\%)$ & - & 11.2 & 26.2 & 33.9 \\
\hline
\end{tabular}

Table 14

Ultimate strength values for UT2E50\% Model with different thicknesses

\begin{tabular}{ccccc}
\hline Plate thickness $(\mathrm{mm})$ & $\mathbf{8 . 5}$ & $\mathbf{1 0}$ & $\mathbf{1 3}$ & $\mathbf{1 6}$ \\
\hline Ultimate strength $(\mathrm{MPa})$ & 161.7 & 182.7 & 216.8 & 241.1 \\
Difference $(\%)$ & - & 11.5 & 25.4 & 32.9 \\
\hline
\end{tabular}

\section{CONCLUSION}

This main objective of the present paper has been to numerically investigate the ultimate compressive strength characteristics of an unstiffened steel plate due to transverse cracking damages located in the middle. In this regard, a series of non-linear finite element (FE) calculations were carried out using ANSYS commercial finite element code. The obtained FE results/observations confirm that the crack length and crack location can considerably affect the ultimate strength level. Also, the critical type of cracks can depend on the value of plate slenderness ratio.

\section{REFERENCES}

Paik, J.K., Thayamballi, A.K. and Lee, J.M. (2004). 'Effect of initial deflection shape on the ultimate strength behaviour of welded steel plates under biaxial compressive loads'. Journal of Ship Research, Vol. 48, No. 1, March 2004, pp. 45-60.

Paik, J.K. and Sohn, J.M. (2009). 'Effects of welding residual Stresses on high tensile steel plate ultimate strength; Nonlinear finite element method investigations'. The $28^{\text {th }}$ International Conference on Offshore Mechanics and Arctic Engineering, OMAE2009, Honolulu, Hawaii.

Fang, W., Feng-luo, C. and Wei-cheng, C. (2010). 'Applicability of the improved crack growth rate model and its parameters estimation method'. Journal of Ship Mechanics, Vol. 14, No. 3, Mar. 2010, pp. 252-262.

Xiao-dong, X., Wei-cheng, C. and Xiao-ping, H. (2010). 'A comparison between two models of fatigue crack growth under overload'. Journal of Ship Mechanics, Vol. 14, No. 3, Mar. 2010, pp. 263-271.

Brighenti, R. 'Numerical buckling analysis of compressed or tensioned cracked thin plates'. Engineering Structures, Vol. 27, 2005, pp. 265-276.

Alinia, M.M., Hoseinzadeh, S.A.A. and Habashi, H.R. (2007). 'Influence of central cracks on buckling and post-buckling behaviour of shear panels'. Thin-Walled Structures, Vol. 45, 2007, pp.422-431. 
Alinia, M.M., Hoseinzadeh, S.A.A. and Habashi, H.R. (2007). 'Numerical modelling for buckling analysis of cracked shear panels'. Thin-Walled Structures, Vol. 45, 2007, pp. 1058-1067.

Khedmati, M.R., Edalat, P. and Javidruzi, M. (2009). 'Sensitivity analysis of the elastic buckling of cracked plate elements under axial compression'. Thin-Walled Structures, Vol. 47, 2009, pp. 522-536.

Paik, J.K., Satish Kumar, Y.V. and Lee, J.M. (2005). 'Ultimate strength of cracked plate elements under axial compression or tension'. Thin-Walled Structures, Vol. 43, 2005, pp. 237272.

Paik, J.K. (2008). 'Residual ultimate strength of steel plates with longitudinal cracks under axial compression: Experiments'. Ocean Engineering, Vol. 35, 2008, pp. 17751783.

Paik, J.K. (2009). 'Residual ultimate strength of steel plates with longitudinal cracks under axial compression: Nonlinear finite element method investigations'. Ocean Engineering, Vol. 36, 2009, pp. 266-276.

ANSYS (2009). 'User's manual (version 12.1)', Swanson Analysis Systems Inc., 2009, Houston. 